\title{
ANÁLISE DAS MARGENS DE COMERCIALIZAÇÃO DA BATATA INGLESA NO DISTRITO FEDERAL
}

\author{
Amanda Cristina Gaban Filippi ${ }^{1}$, Cleyzer Adrian da Cunha ${ }^{2}$ \\ ${ }^{1}$ Doutoranda em Agronegócio pela UFG, Universidade Federal de Goiás, Programa \\ de Pós-Graduação em Agronegócio, Goiânia, Brasil. E-mail: \\ amandagaban@hotmail.com. \\ ${ }^{2}$ Prof. Doutor do curso em Agronegócio da UFG, Universidade Federal de Goiás, \\ Programa de Pós-Graduação em Agronegócio, Goiânia, Brasil.

\section{Recebido em: 06/04/2019 - Aprovado em: 10/06/2019 - Publicado em: 30/06/2019 DOI: 10.18677/EnciBio_2019A5}

\begin{abstract}
RESUMO
A batata é uma das principais culturas consumidas no mundo e de grande importância no Brasil, tendo destaque na produção anual entre as hortaliças. Contudo, a maior parte da comercialização da produção é realizada através de intermediários, que recebem a maior parte do lucro com a venda e repassam um adicional de custo no produto para o consumidor final. Além disso, existe a necessidade de melhor organização e análise da produção e comercialização entre os produtores rurais com o intuito de melhorarem a competitividade frente ao atacado e varejo. O objetivo desse artigo foi analisar as margens de comercialização da batata inglesa no período de novembro de 2015 a abril de 2017 . Especificamente, pretendeu-se analisar a flutuação de preços da batata inglesa e a elasticidade de transmissão no período supracitado. Os resultados revelaram diferenças significativas e queda nos preços da batata inglesa a nível de comercialização varejo, atacado e produtor na maior parte do período analisado. Além disso, a participação do produtor é de apenas 33,54\% em todo o período, sendo que $66,46 \%$ do valor da venda do produto final fica com o varejo e o atacado. Percebe-se a instabilidade entre os agentes de comercialização e as elasticidades revelaram influência entre os agentes da comercialização.
\end{abstract}

PALAVRAS-CHAVE: Agronegócio da Batata Inglesa, Comercialização, Preços.

\section{ANALYSIS OF THE MARKETING MARGINS OF ENGLISH POTATOES IN FEDERAL DISTRICT}

\begin{abstract}
The potato is one of the main crops consumed in the world and of great importance in brazil, being highlighted in the annual production among the vegetables. However, most of the commercialization of the production is carried out through intermediaries, who receive most of the profit from the sale and pass on an additional cost in the product to the final consumer. In addition, there is a need for better organization and analysis of production and marketing among rural producers with the aim of improving their competitiveness in relation to wholesale and retail. The objective of
\end{abstract}


this article was to analyze the marketing margins of the potato from november 2015 to april 2017. Specifically, it was intended to analyze the fluctuation of english potato prices and the elasticity of transmission in the above-mentioned period. the results revealed significant differences and fall in the prices of potatoes at retail, wholesale and producer level for most of the analyzed period. In addition, the producer's share is only $33.54 \%$ throughout the period, with $66.46 \%$ of the value of the sale of the final product being with retail and wholesale. The instability between the agents of commercialization and the elasticities revealed an influence among the agents of the commercialization.

KEYWORDS: Agribusiness of the english potato, commercialization, price.

\section{INTRODUÇÃO}

A batata é uma das principais culturas consumidas no mundo (SILVA et al., 2016), e de grande importância no Brasil, tendo destaque na produção anual entre as hortaliças com expectativa de safra de 3,97 milhões de toneladas produzidas numa área de 130 mil hectares em 2017 (IBGE, 2017). Nas últimas safras, a produção obtida com a cultura passou de 3,87 milhões de toneladas em 2015 para aproximadamente 3,93 milhões de toneladas em 2016, com destaque para $1^{\underline{a}}$ e $2^{\underline{a}}$ safra do produto em 2016, com 1,85 milhões de toneladas e 1,14 milhões de toneladas, respectivamente (IBGE, 2017). Além disso, percebeu-se a diminuição na área plantada da cultura, com redução de 147,8 mil hectares na safra de 2007 para 134,2 mil hectares em 2016. Tal fato é positivo, já que, a produtividade da cultura aumentou de $24.036 \mathrm{Kg} / \mathrm{ha}$ em 2007, para $29.332 \mathrm{Kg} / \mathrm{ha}$ em 2016 (IBGE, 2017).

Sabe-se que a maior parte da comercialização da produção é realizada através de intermediários, que acabam recebendo a parte do lucro com a venda e repassam um adicional de custo no produto para o consumidor final. Além disso, existe a necessidade de melhor organização e análise da produção e comercialização entre os produtores rurais com o intuito de que sejam competitivos em relação ao atacado e varejo (REICHERT et al., 2013). De acordo com Mendes e Padilha Junior (2007) esse incremento no preço final é justificado pela teoria econômica como uma interação entre consumidores, produtores e intermediários. Como existem serviços e funções realizadas durante todo o processo de comercialização, haverá um aumento no custo final do produto, já que esse produto é negociado e repassado entre diferentes atores. Assim, torna-se fundamental compreender a formação e transmissão de custos e preços ao longo dos diferentes níveis do sistema de comercialização (MENDES; PADILHA JUNIOR, 2007; SILVA; LAGES, 2011; CARVALHAES et al., 2015; CUNHA et al., 2016; ZANIN; MEYER, 2018).

O objetivo desse trabalho foi analisar as margens de comercialização da batata inglesa no período de novembro de 2015 a abril de 2017. Especificamente, pretendeu-se analisar a flutuação de preços da batata inglesa e a elasticidade de transmissão no período supracitado. $\mathrm{O}$ trabalho foi dividido em quatro seções. A primeira seção descreve os materiais e métodos utilizados para atingir o objetivo desse trabalho. A segunda seção analisa e discute os resultados do estudo. E por fim, a última seção apresenta as considerações finais, sugestões de estudos futuros e limitações da pesquisa. 


\section{MATERIAL E MÉTODOS}

A coleta de dados se deu a partir da base de dados da CONAB (Companhia Nacional de Abastecimento) relativo aos preços de batata em relação ao varejo, atacado e produtor no período de novembro de 2015 a abril de 2017. Para obter os preços reais, foi realizado o deflacionamento dos preços nominais através do Índice Geral de Preços (IGP-DI), que é calculado pela Fundação Getúlio Vargas e disponibilizado pelo IPEADATA, o qual expressa tanto os preços ao consumidor final como no interior das cadeias produtivas e canais de comercialização (preços atacado) (SOUZA; VIANA, 2007; FGV, 2017).

Em seguida foram calculadas as margens de comercialização, que é a diferença de preço de um nível de mercado a outro (MENDES; FREITAS; OLIVEIRA JUNIOR, 2004; PADILHA JUNIOR, 2007), conforme equação:

$$
M=C+L
$$

Onde: C é o Custo; L é o Lucro (ou prejuízo do intermediário).

Nesse trabalho, foram realizados os cálculos das margens total e relativa a para varejo, produtor e atacado de acordo com o modelo de Mendes e Padilha Junior (2007) para comercialização de produtos agrícolas. As equações do cálculo das margens em valores absolutos são:

$$
\mathrm{MT}=\mathrm{Pv}-\mathrm{Pp}
$$

Onde: MT é a Margem total (valor absoluto); Pv é o Preço varejo; Pp é o Preço produtor.

$$
\mathrm{MA}=\mathrm{Pa}-\mathrm{Pp}
$$

Onde: MA é a Margem de Atacado (valor absoluto); Pa é o Preço atacado; Pp é o Preço produtor.

$$
\mathrm{MV}=\mathrm{Pv}-\mathrm{Pa}
$$

Onde: MV é a Margem de Varejo (valor absoluto); Pv é o Preço varejo; Pa é o Preço atacado.

As equações do cálculo das margens em valores relativos (\%) são:

$$
M T^{\prime}=[(P v-P p)] \div P v \times 100
$$

Onde: $\mathrm{MT}^{\prime}$ é a Margem total (valor relativo \%); Pv é o Preço varejo; Pp é o Preço produtor.

$$
M A^{\prime}=[(P a-P p)] \div P v \times 100
$$

Onde: MA' é a Margem de Atacado (valor relativo \%); Pa é o Preço atacado; Pp é o Preço produtor; Pv é o Preço varejo.

$$
M V^{\prime}=[(P v-P a)] \div P v \times 100
$$

Onde: MV' é a Margem de Varejo (valor relativo \%); Pv é o Preço varejo; Pa é o Preço atacado. 
De forma complementar foi calculada a Participação do Produtor (PP\%) conforme equação:

$$
\mathrm{PP} \%=100-\mathrm{MT}
$$

Onde: PP\% é a Participação do Produtor (\%);MT é a Margem Total.

Em sequência, foi realizado o teste da raiz unitária de Dickey-Fuller Aumentado (ADF) e calculada a elasticidade de transmissão dos preços. O teste da raiz unitária verificou que a série dos preços da batata é estacionária ou nãoestacionária (GUJARATI, 2006). De acordo com Lobo e Silva Neto (2011) é comum as séries econômicas serem não estacionárias, de forma que os preços não se comportam de maneira uniforme num determinado período do tempo, ou seja, os preços podem não se encontrar em equilíbrio constante. A seguir são mostrados matematicamente o teste da Raiz Unitária (GUJARATI, 2006, p. 652).

$$
Y_{t}=\rho Y_{t-1}+u_{t} \quad-1 \leq \rho \leq 1
$$

Onde: $Y_{t}$ é uma série temporal e $u_{t}$ é um termo de erro de ruído aleatório. De acordo com o autor, se $\rho$ estimado for igual a $1, Y_{t}$ é não estacionária.

A partir dessa equação, pode-se subtrair $Y_{t-1}$ de ambos os lados:

$$
\Delta Y_{t}=\delta Y_{t-1}+u_{t}
$$

Onde: $\Delta Y_{\tau}=Y_{\tau}-Y_{t-1}$ e $\delta=\rho-1$. Assim, testa-se a hipótese nula de que $\delta=0$. Se $\delta=0$, então $\rho=1$, ou seja, existe raiz unitária, e, portanto, a série temporal é nãoestacionária.

Caso a série seja não estacionária $(\delta=0)$, a equação se torna:

$$
\Delta Y_{t}=\left(Y_{t}-Y_{t-1}\right)=u_{t}
$$

Onde: $u_{t}$ é um termo de erro ruído branco, é estacionário, e as primeiras diferenças da série temporal de passeio aleatório são estacionárias.

Contudo, em hipótese nula de $\delta=0$, o valor t estimado do coeficiente de $Y_{t-1}$ segue a estatística tau (T) ou teste Dickey-Fuller (DF) (GUJARATI, 2006). Sabe-se que não se consideram modelos que apresentam deslocamentos ou tendência (determinística ou estocástica). Dessa forma, o teste de DF pode ser estimado em três formas alternativas (GUJARATI, 2006; SANTOS, et al., 2007): (a) $Y_{1}$ é um passeio aleatório $\left(\Delta Y_{1}=\delta Y_{t-1}+u_{t}\right)$; (b) $Y_{1}$ é um passeio aleatório com deslocamento $\left(\Delta Y_{1}=\beta_{1}+\delta Y_{t-1}+u_{t}\right)$; e, (c) $Y_{1}$ é um passeio aleatório com deslocamento em torno de uma tendência estocástica $\left(\Delta Y_{1}=\beta_{1}+\beta_{2} t+\delta Y_{t-1}+u_{t}\right)$. Em cada caso, a hipótese nula é que $\delta=0$ (existe raiz unitária e a série temporal é não estacionária). Adicionalmente, caso $u_{t}$ apresentar correlação, é realizado o teste de DFAumentado:

$$
\Delta Y_{1}=\beta_{1}+\beta_{2} t+\delta Y_{t-1}+\sum_{i=i}^{m} a_{i} \Delta Y_{t-1}+\varepsilon_{t}
$$

Onde: $\varepsilon_{t}$ é um termo de ruído branco puro e se continua testando se $\delta=0$.

Por fim, a elasticidade de transmissão de preços em um sistema de comercialização é uma relação que mede a sensibilidade de uma variável 
dependente diante de uma alteração no valor de uma de suas variáveis independentes (MENDES; PADILHA JUNIOR, 2007). Isto significa que, se a elasticidade-preço for menor que 1, existirá uma transmissão imperfeita, e dessa forma, haverá ganhos de margem em um dos elos da cadeia (LOBO; SILVA NETO, 2011).

De forma complementar, Mendes e Padilha Junior (2007) descrevem que a elasticidade de transmissão de preços na comercialização analisa o comportamento dos preços nos diferentes níveis do mercado. Assim, a elasticidade mostrará quanto o preço num nível de mercado irá variar percentualmente quando o preço em um outro patamar variar 1\% (MENDES; PADILHA JUNIOR, 2007):

$$
\text { Elasticidade }(\epsilon)=\frac{\Delta \% \text { na variável dependente }(\mathrm{Y})}{\Delta \% \text { na variável independente }(\mathrm{X})}=\frac{\frac{\Delta Y}{\mathrm{Y}}}{\frac{\Delta \mathrm{X}}{\mathrm{X}}}=\frac{\Delta \mathrm{Y}}{\mathrm{Y}} \cdot \frac{\mathrm{X}}{\Delta \mathrm{X}}=\frac{\Delta \mathrm{Y}}{\Delta \mathrm{X}} \cdot \frac{\mathrm{X}}{\mathrm{Y}}
$$

Matematicamente, tem-se que a elasticidade de transmissão de preços na comercialização é (MENDES; PADILHA JUNIOR, 2007):

$$
\epsilon_{\mathrm{vp}}=\frac{\Delta \mathrm{Pv}}{\Delta \mathrm{Pp}} \cdot \frac{\mathrm{Pp}}{\overline{\mathrm{PV}}}
$$

Onde: $\epsilon_{\mathrm{vp}}$ é a Elasticidade de transmissão de preço (varejo-produtor); Pv é o

Preço de varejo; Pp é o Preço pago aos produtores.

$$
\epsilon_{\mathrm{ap}}=\frac{\Delta \mathrm{Pa}}{\Delta \mathrm{Pp}} \cdot \frac{\mathrm{Pp}}{\mathrm{Pa}}
$$

Onde: $\epsilon_{\mathrm{ap}}$ é a Elasticidade de transmissão de preço (atacado-produtor); Pa é o Preço de atacado; Pp é o Preço pago aos produtores.

$$
E_{\text {va }}=\frac{\Delta \mathrm{PV}}{\Delta \mathrm{Pa}} \cdot \frac{\mathrm{Pa}}{\mathrm{Pv}}
$$

Onde: $\in_{\mathrm{va}}$ é a Elasticidade de transmissão de preço (varejo-atacado); Pv é o

Preço de varejo; Pa é o Preço de atacado. 
Assim, quando $\epsilon_{v p}<1$ (impacto inelástico), as variações no preço do varejo

são menos do que proporcionais às variações do preço do produtor. Se o preço do produtor aumentar $1 \%$, o preço ao consumidor aumentará menos de $1 \%$. Por outro

lado, quando $\epsilon_{\mathrm{vp}}>1$ (impacto elástico), as variações do preço do produtor são

transmitidas mais do que proporcionalmente ao consumidor. E por fim, quando $\epsilon_{\mathrm{vp}}=$

1 (impacto unitário), as variações no preço do produtor são transmitidas nas mesmas proporções para o consumidor (MENDES; PADILHA JUNIOR, 2007). Para Gujarati (2006), a elasticidade de transmissão de preço pode ser demonstrada pelo modelo de regressão exponencial, expresso em:

$$
\ln Y i=\ln \beta 1+\beta 2 \ln X i+u i
$$

Onde: In = logaritmo natural (isto é, logaritmo com base e $=2,718$ ).

Reescrevendo o modelo tem-se:

$$
\ln Y i=\alpha+\beta 2 \ln X i+u i
$$

Onde: $\alpha=\ln \beta 1$, este modelo é linear nos parâmetros $\alpha$ e $\beta 2$, linear nos logaritmos $\mathrm{Y}$ e X, e pode ser estimado mediante uma regressão de MQO. Dada essa linearidade, esses modelos são denominados modelos log-log, duplo-log ou loglineares (GUJARATI, 2006, p. 142). Juntando os pressupostos de Gujarati (2006) e Mendes e Padilha Junior (2007), tem-se que as elasticidades de transmissão de preços ao longo da cadeia são (CARVALHAES et al., 2015):

$$
\begin{gathered}
\log \mathrm{Pp}=\log \alpha_{1}+\beta_{1} \log \mathrm{Pa}+\beta_{2} \log \mathrm{Pv}+\varepsilon_{1} \\
\log \mathrm{Pa}=\log \alpha_{1}+\beta_{1} \log \mathrm{Pp}+\beta_{2} \log \mathrm{Pv}+\varepsilon_{1} \\
\log \mathrm{Pv}=\log \alpha_{1}+\beta_{1} \log \mathrm{Pp}+\beta_{2} \log \mathrm{Pa}+\varepsilon_{1}
\end{gathered}
$$

Onde: $\log \mathrm{Pp}, \log \mathrm{Pa}$ e $\log \mathrm{Pv}$ são as elasticidades de transmissão de preços do produtor, do atacado e do varejo, respectivamente; $\beta_{1}$ e $\beta_{2}$ são coeficientes de elasticidade de transmissão de preços; $\varepsilon_{1}$ é o erro aleatório da equação; e, $\alpha_{1}$ é o termo constante da equação. De acordo com Carvalhaes et al. (2015), os preços do produtor são influenciados pelos preços do atacado e do varejo na equação 19 de elasticidade de transmissão de preços. Vale lembrar que os procedimentos econométricos para os dados foram calculados através dos programas EXCEL e 
EVIEWS, com a sequente elaboração de quadros, tabelas e gráficos para analisar e mostrar os resultados.

\section{RESULTADOS E DISCUSSÃO \\ Evolução dos Preços e Margens de Comercialização}

Os preços deflacionados a preços constantes do mês atual (abril/2017) de batata em relação a comercialização varejo, atacado e produtor são apresentados na Figura 1.

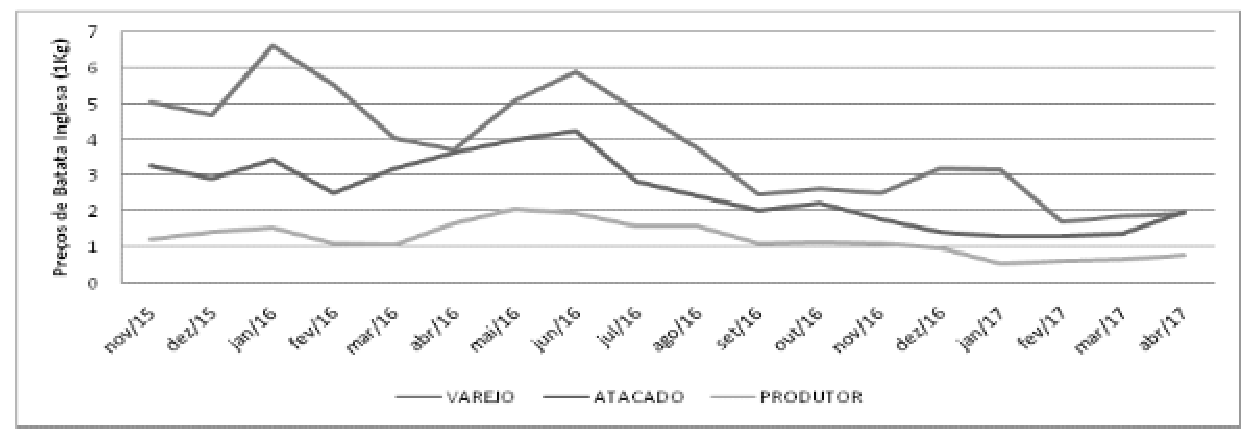

FIGURA 1 - Série de preços varejo, atacado e produtor para batata (novembro/ 2015 a abril/2017).

Fonte: Resultados da pesquisa (2018).

$\mathrm{Na}$ Figura 1, percebem-se diferenças significativas, bem como, queda nos preços da batata na comercialização varejo, atacado e produtor, considerando o período de janeiro de 2016 a fevereiro de 2017. As quedas nos preços são explicadas principalmente pelas condições climáticas favoráveis para a cultura, já que, a ocorrência de chuvas nos períodos certos para a cultura proporcionaram um produto de maior qualidade, e pela safra recorde da batata e alta produtividade no final de 2016 (CEPEA/ESALQ, 2016; PROHORT/CEASA, 2016). Assim, como a oferta do produto aumentou no mercado, proporcionada pela safra recorde e favorável, os preços do produto reduziram, passando de $R \$ 5,05$ para $R \$ 1,97$ no varejo, de $R \$ 3,28$ para $R \$ 2,01$ no atacado, e de, $R \$ 1,22$ para $R \$ 0,79$ no produtor.

Adicionalmente, a partir de fevereiro de 2017 , os preços do produto começaram a aumentar. De acordo com o CEPEA/ESALQ (2016), devido aos baixos preços pagos pelo produto que podem ser observados na Figura 1, entre julho de 2016 e fevereiro de 2017 , os produtores reduziram os plantios no período de abril a maio de 2017. Dessa forma, com a baixa oferta do produto no mercado, os preços começaram a subir.

Já as diferenças de preços nos três níveis de comercialização são explicadas pelos agentes envolvidos na venda do produto. Considerando esse caso e em todo o período considerado, os preços do produtor são sempre mais baixos que em relação ao varejo e atacado. Isso se deve ao tipo de comercialização envolvida. Como a comercialização varejo e atacado têm mais de um agente envolvido na transação, o preço sempre será mais alto que o preço produtor. Dessa forma, o repasse desse valor nunca será voltado integralmente para o produtor rural. Através do cálculo da participação real do produtor (PP), é possível perceber essa situação (Figura 2). 


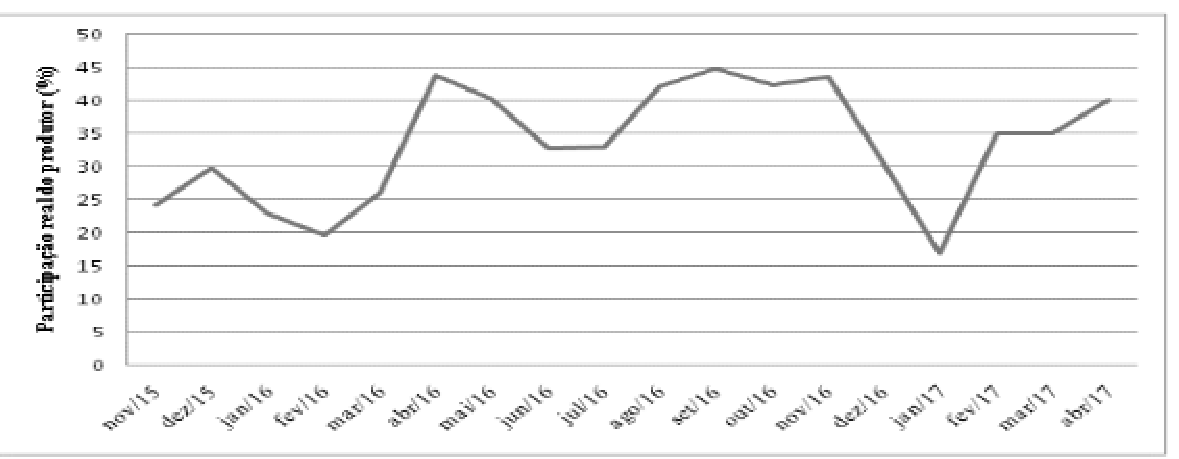

FIGURA 2 - Participação do Produtor em \%. Fonte: Resultados da pesquisa (2018).

$\mathrm{Na}$ Figura 2, a média do período analisado de quanto o produtor de batata recebeu no processo é de aproximadamente 33,54\%. Isto significa a diferença entre o preço de varejo (Pv) e o preço que o produtor $(\mathrm{Pp})$ recebeu pela venda de seu produto na propriedade rural, o que no presente caso é um valor relativamente baixo que chega ao produtor. Percebe-se que grande parte do valor de venda do produto final não fica com o produtor rural, mas sim, com o varejo e atacado.

Além disso, verificou-se em todo período menor participação do produtor em meados dos meses de janeiro, com 23,04\% de participação em janeiro de 2016 e $16,97 \%$ de participação em janeiro de 2017. De acordo com o calendário de comercialização do CEASA/DF, a cultura da batata registra uma intensidade forte de comercialização nesse período, representado por maior oferta do produto no mercado e tendência de preços baixos. Pressupõe-se assim, que a margem de ganho do produtor se reduz para compensar os baixos preços pagos para o varejo.

Segundo a Associação Brasileira de Batata do Brasil (ABBA), a comercialização de diversos produtos agrícolas no país é o principal problema para o produtor rural. No caso da batata, a desorganização dos produtores de batata é uma característica aproveitada pelas grandes redes de varejo, sendo que o produto é comprado por valores baixos do produtor e vendido com acréscimos ao consumidor (REICHERT et al., 2013). Tal afirmação corrobora com a análise dessa pesquisa.

Adicionalmente, são apresentadas as margens em valores absolutos e relativos (Quadro 1).

QUADRO 1 - Margens em valores absolutos e relativos para batata.

\begin{tabular}{|c|c|c|c|c|c|r|r|}
\hline \multirow{2}{*}{ Período } & \multicolumn{9}{|c|}{ MARGEM } \\
\cline { 2 - 8 } & $\begin{array}{c}\text { VALOR ABSOLUTO } \\
\text { Total (MT) }\end{array}$ & $\begin{array}{c}\text { Margem } \\
\text { Atacado } \\
\text { (MA) }\end{array}$ & $\begin{array}{c}\text { Margem } \\
\text { Varejo } \\
\text { (MV) }\end{array}$ & $\begin{array}{c}\text { Margem } \\
\text { Total } \\
\text { (MT') }\end{array}$ & $\begin{array}{c}\text { Margem } \\
\text { Atacado } \\
\text { (MA') }\end{array}$ & $\begin{array}{c}\text { Margem } \\
\text { Varejo } \\
\text { (MV') }\end{array}$ & $\begin{array}{l}\text { Participação } \\
\text { do Produtor } \\
\text { (PP\%) }\end{array}$ \\
\hline nov/15 & 3,828576 & 2,0555457 & 1,7730299 & 75,722543 & 40,655106 & 35,067437 & 24,2774566 \\
\hline dez/15 & 3,296995 & 1,5057916 & 1,7912031 & 70,083682 & 32,008368 & 38,075314 & 29,916318 \\
\hline jan/16 & 5,094611 & 1,8872553 & 3,2073561 & 76,957164 & 28,508124 & 48,44904 & 23,042836 \\
\hline fev/16 & 4,44264 & 1,4255504 & 3,0170895 & 80,246914 & 25,749559 & 54,497354 & 19,7530864 \\
\hline mar/16 & 2,991304 & 2,1057208 & 0,8855835 & 73,786408 & 51,941748 & 21,84466 & 26,2135922 \\
\hline abr/16 & 2,099641 & 1,9813515 & 0,1182896 & 56,200528 & 53,034301 & 3,1662269 & 43,7994723 \\
\hline mai/16 & 3,031155 & 1,9226741 & 1,1084805 & 59,65251 & 37,837838 & 21,814672 & 40,3474903 \\
\hline jun/16 & 3,958334 & 2,2952503 & 1,6630839 & 67,272727 & 39,008264 & 28,264463 & 32,7272727 \\
\hline jul/16 & 3,238091 & 1,2340287 & 2,0040627 & 67,075665 & 25,562372 & 41,513292 & 32,9243354 \\
\hline ago/16 & 2,172541 & 0,8690165 & 1,3035247 & 57,894737 & 23,157895 & 34,736842 & 42,1052632 \\
\hline set/16 & 1,371966 & 0,9179341 & 0,4540319 & 55,15873 & 36,904762 & 18,253968 & 44,8412698 \\
\hline out/16 & 1,530501 & 1,1059105 & 0,4245907 & 57,620818 & 41,635688 & 15,98513 & 42,3791822 \\
\hline
\end{tabular}




\begin{tabular}{|c|r|r|r|r|r|r|r|} 
nov/16 & 1,43448 & 0,6727218 & 0,7617585 & 56,420233 & 26,459144 & 29,961089 & 43,5797665 \\
\hline dez/16 & 2,232972 & 0,4721703 & 1,7608017 & 69,41896 & 14,678899 & 54,740061 & 30,5810398 \\
\hline jan/17 & 2,643492 & 0,7763414 & 1,8671502 & 83,024691 & 24,382716 & 58,641975 & 16,9753086 \\
\hline fev/17 & 1,116677 & 0,7213929 & 0,3952838 & 64,942529 & 41,954023 & 22,988506 & 35,0574713 \\
\hline mar/17 & 1,226237 & 0,7218978 & 0,5043396 & 64,921466 & 38,219895 & 26,701571 & 35,078534 \\
\hline abr/17 & 1,18 & 1,22 & $-0,04$ & 59,898477 & 61,928934 & $-2,030457$ & 40,1015228 \\
\hline Média & 2,60 & 1,33 & 1,28 & 66,46 & 35,76 & 30,71 & 33,54 \\
\hline \multicolumn{7}{|c|}{ Fonte: Resula } &
\end{tabular}

De acordo com os resultados do Quadro 1, do preço final pago pelo consumidor no mercado $66,46 \%$ em média ficou no sistema para remunerar os serviços de comercialização, chegando a 83,02\% em janeiro de 2017. Nesse contexto, a participação do atacado foi de aproximadamente $35,76 \%$ em média no período, chegando a $61,93 \%$ em abril de 2017 . Isto significa que a cada $R \$ 1,00$ gasto pelo consumidor na aquisição de batata em média, $R \$ 0,3354(33,54 \%)$ vai para o produtor e $\mathrm{R} \$ 0,6646(66,46 \%)$ vai para os agentes da comercialização, 0 atacado e varejo. Praticamente, menos da metade do valor final fica para o produtor.

Para Silva Júnior et al. (2011) e Cunha et al. (2016), a margem total de comercialização ( $\mathrm{MT}^{\prime}$ ) relativamente alta indica que os valores ou serviços prestados pelos intermediários são caros e que os mesmos ficam com uma parcela maior do valor final do produto. Além disso, na Figura 3 se observa graficamente as margens relativas ao longo do período de análise.

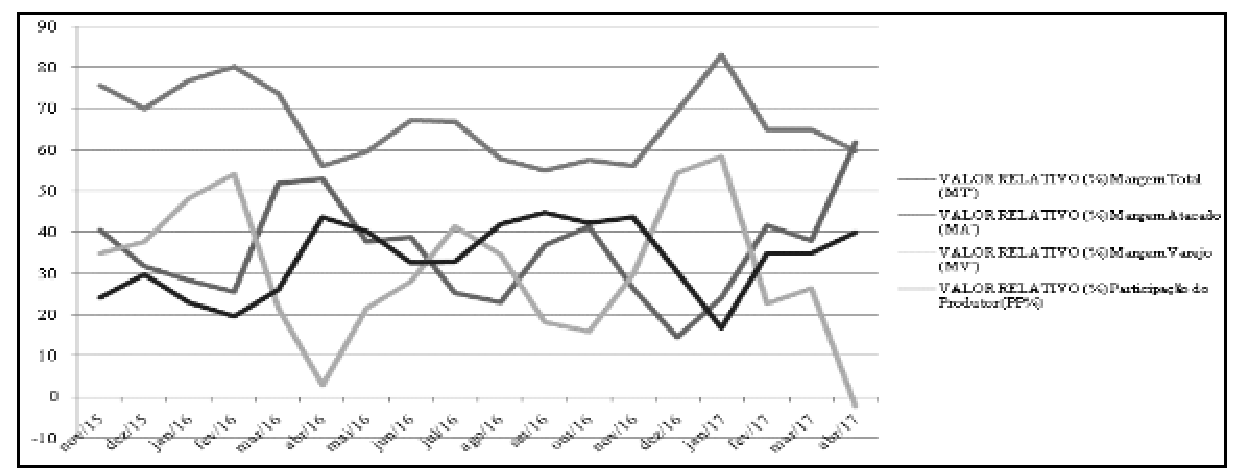

FIGURA 3 - Margens relativas de comercialização da batata (novembro/ 2015 a abril/2017).

Fonte: Resultados da pesquisa (2018).

Percebe-se instabilidade da participação do produtor $(33,54 \%)$, do atacado $(35,76 \%)$ e do varejo $(30,71 \%)$ em média. Existe variação das margens relativas ao longo do período, o que demonstra não consolidação entre os agentes de comercialização da batata.

\section{Teste de Raiz Unitário Aumentado de Dickey-Fuller}

Dos testes de Raiz Unitária Aumentado para as séries de preços produtor, atacado e varejo, de batata no período de novembro de 2015 a abril de 2017, foram realizados com os seguintes modelos: (i) com intercepto (passeio aleatório com deslocamento); e, (ii) com tendência e intercepto (passeio aleatório com deslocamento e tendência). Além disso, os testes foram feitos em $1^{\underline{a}}$ diferença e $2^{\underline{a}}$ diferença.

O Quadro 2 mostra os resultados do teste de Raiz Unitária em $1^{\text {a }}$ diferença com intercepto. $\mathrm{O}$ valor da estimativa Tau para a série de dados preço produtor $\mathrm{e}$ preço atacado foi $-3,182$ e -3,901, respectivamente, e os valores da estatística Dickey-Fuller aos níveis $1 \%$ e 5\% foram, respectivamente, -3,920 e -3,065. Como, a 
estatística Tau é menor que o valor crítico a $5 \%$, rejeita-se a hipótese nula de raiz unitária, isto é, a série do preço produtor e preço atacado em $1^{\text {a }}$ diferença é estacionária. Já a série de dados do preço varejo, é estacionária com valor crítico a $1 \%$ e $5 \%$, ou seja, rejeita-se a hipótese nula de raiz unitária.

QUADRO 2 - Resultados do Teste da raiz unitária em $1^{\text {a }}$ diferença (intercepto).

\begin{tabular}{|c|c|c|c|}
\hline \multirow{2}{*}{$\begin{array}{l}\text { Modelo 1st } \\
\text { diferença }\end{array}$} & \multicolumn{3}{|c|}{ t-Statistic (Tau) } \\
\hline & $\mathrm{Pp}$ & $\mathrm{Pa}$ & $\mathrm{PV}$ \\
\hline Intercepto & $-3,182$ & $-3,901$ & $-4,226$ \\
\hline \multicolumn{4}{|c|}{ Valor Crítico } \\
\hline $\begin{array}{l}\text { Valor crítico } \\
\text { teste } 1 \%\end{array}$ & $-3,920$ & $-3,920$ & $-4,004$ \\
\hline $\begin{array}{l}\text { Valor crítico } \\
\text { teste } 5 \%\end{array}$ & $-3,065$ & $-3,065$ & $-3,098$ \\
\hline Resultado & $\begin{array}{l}\text { Série estacionária com valor } \\
\text { crítico de } 5 \%(-3,182 \text { é MENOR } \\
\text { que -3,065). Rejeita-se a } \\
\text { hipótese NULA de raiz unitária. }\end{array}$ & $\begin{array}{l}\text { Série estacionária com valor } \\
\text { crítico de } 5 \%(-3,901 \text { é MENOR } \\
\text { que -3,065). Rejeita-se a } \\
\text { hipótese NULA de raiz unitária. }\end{array}$ & $\begin{array}{l}\text { Série estacionária com } \\
\text { valor crítico de } 5 \% \text { e } 1 \% \text {. } \\
\text { Rejeita-se a hipótese } \\
\text { NULA de raiz unitária. }\end{array}$ \\
\hline
\end{tabular}
Fonte: Resultados da pesquisa (2018).

O Quadro 3 mostra os resultados do teste de Raiz Unitária em $1^{\text {a }}$ diferença com tendência e intercepto. $O$ valor da estimativa Tau para a série de dados preço varejo foi $-4,004$, e os valores da estatística Dickey-Fuller aos níveis $1 \%$ e $5 \%$ foram, respectivamente, $-4,800$ e $-3,791$. Como, a estatística Tau é menor que o valor crítico a 5\%, rejeita-se a hipótese nula de raiz unitária, isto é, a série do preço varejo em 1a diferença é estacionária. Já a série de dados do preço produtor e atacado, é não estacionária com valor crítico a $1 \%$ e 5\%, ou seja, não rejeita-se a hipótese nula de raiz unitária (tem raiz unitária).

QUADRO 3 - Resultados do Teste da raiz unitária em $1^{\text {a }}$ diferença (tendência e interceptação).

\begin{tabular}{|c|c|c|c|}
\hline \multirow{2}{*}{$\begin{array}{ll}\begin{array}{l}\text { Modelo } \\
\text { diferença }\end{array} & \text { 1st } \\
\end{array}$} & \multicolumn{3}{|c|}{ t-Statistic (Tau) } \\
\hline & $\mathrm{Pp}$ & $\mathrm{Pa}$ & $\mathrm{Pv}$ \\
\hline $\begin{array}{l}\text { Tendência e } \\
\text { Intercepção }\end{array}$ & $-3,033$ & $-3,750$ & $-4,004$ \\
\hline \multicolumn{4}{|c|}{ Valor Crítico } \\
\hline $\begin{array}{l}\text { Valor crítico } \\
\text { teste } 1 \%\end{array}$ & $-4,667$ & $-4,667$ & $-4,800$ \\
\hline $\begin{array}{l}\text { Valor crítico } \\
\text { teste } 5 \%\end{array}$ & $-3,733$ & $-3,733$ & $-3,791$ \\
\hline Resultado & $\begin{array}{l}\text { Série não estacionária com } \\
\text { valor crítico de } 5 \% \text { e } 1 \% \text {. Não } \\
\text { rejeita-se a hipótese NULA de } \\
\text { raiz unitária. }\end{array}$ & $\begin{array}{l}\text { Série não estacionária com } \\
\text { valor crítico de } 5 \% \text { e } 1 \% \text {. Não } \\
\text { rejeita-se a hipótese NULA de } \\
\text { raiz unitária. }\end{array}$ & $\begin{array}{l}\text { Série estacionária com } \\
\text { valor crítico de } 5 \% \text {. Rejeita- } \\
\text { se a hipótese NULA de raiz } \\
\text { unitária. }\end{array}$ \\
\hline
\end{tabular}

Fonte: Resultados da pesquisa (2018).

O Quadro 4 mostra os resultados do teste de Raiz Unitária em $2^{-a}$ diferença com intercepto. O valor da estimativa Tau para a série de dados preço produtor e preço varejo foi $-3,728$ e $-3,732$, respectivamente, e os valores da estatística DickeyFuller aos níveis 1\% e 5\% foram, respectivamente, -4,057 e -3,119, e -4,121 e 3,144 .. Como, a estatística Tau é menor que o valor crítico a $5 \%$, rejeita-se a hipótese nula de raiz unitária, isto é, a série do preço produtor e preço varejo em $2^{\underline{a}}$ 
diferença é estacionária. Já a série de dados do preço atacado, é estacionária com valor crítico a $1 \%$ e $5 \%$, ou seja, rejeita-se a hipótese nula de raiz unitária.

QUADRO 4 - Resultados do Teste da raiz unitária em $2^{2}$ diferença (intercepto).

\begin{tabular}{|c|c|c|c|}
\hline \multirow{2}{*}{$\begin{array}{l}\text { Modelo 2st } \\
\text { diferença }\end{array}$} & \multicolumn{3}{|c|}{ t-Statistic (Tau) } \\
\hline & $\mathrm{Pp}$ & $\mathrm{Pa}$ & $\mathrm{PV}$ \\
\hline Intercepto & $-3,728$ & $-7,181$ & $-3,732$ \\
\hline \multicolumn{4}{|c|}{ Valor Crítico } \\
\hline $\begin{array}{c}\text { Valor crítico } \\
\text { teste } 1 \%\end{array}$ & $-4,057$ & $-3,959$ & $-4,121$ \\
\hline $\begin{array}{c}\text { Valor crítico } \\
\text { teste } 5 \%\end{array}$ & $-3,119$ & $-3,081$ & $-3,144$ \\
\hline Resultado & $\begin{array}{l}\text { Série estacionária com valor } \\
\text { crítico de } 5 \% \text {. Rejeita-se a } \\
\text { hipótese NULA de raiz } \\
\text { unitária. }\end{array}$ & $\begin{array}{l}\text { Série estacionária com valor } \\
\text { crítico de } 5 \% \text { e } 1 \% \text {. Rejeita-se } \\
\text { a hipótese NULA de raiz } \\
\text { unitária. }\end{array}$ & $\begin{array}{l}\text { Série estacionária com valor } \\
\text { crítico de } 5 \% \text {. Rejeita-se a } \\
\text { hipótese NULA de raiz } \\
\text { unitária. }\end{array}$ \\
\hline
\end{tabular}

Fonte: Resultados da pesquisa (2018).

O Quadro 5 mostra os resultados do teste de Raiz Unitária em $2^{\mathrm{a}}$ diferença com tendência e intercepto. $O$ valor da estimativa Tau para a série de dados preço atacado foi -4,282, e os valores da estatística Dickey-Fuller aos níveis $1 \%$ e $5 \%$ foram, respectivamente, -4,992 e -3,875. Como, a estatística Tau é menor que o valor crítico a $5 \%$, rejeita-se a hipótese nula de raiz unitária, isto é, a série do preço atacado em $2^{\text {a }}$ diferença é estacionária. Já a série de dados do preço produtor e varejo, são não estacionárias com valor crítico a $1 \%$ e $5 \%$, ou seja, não rejeita-se a hipótese nula de raiz unitária (tem raiz unitária).

QUADRO 5 - Resultados do Teste da raiz unitária em $2^{\underline{a}}$ diferença (tendência e intercepto).

\begin{tabular}{|c|c|c|c|}
\hline \multirow{2}{*}{$\begin{array}{c}\text { Modelo 2st } \\
\text { diferença }\end{array}$} & \multicolumn{3}{|c|}{ t-Statistic (Tau) } \\
\hline & $\mathrm{Pp}$ & $\mathrm{Pa}$ & Pv \\
\hline $\begin{array}{c}\text { Tendência e } \\
\text { intercepto }\end{array}$ & $-3,502$ & $-4,282$ & $-3,477$ \\
\hline \multicolumn{4}{|c|}{ Valor Crítico } \\
\hline $\begin{array}{c}\text { Valor crítico } \\
\text { teste } 1 \%\end{array}$ & $-4,886$ & $-4,992$ & $-4,992$ \\
\hline $\begin{array}{c}\text { Valor crítico } \\
\text { teste } 5 \%\end{array}$ & $-3,828$ & $-3,875$ & $-3,875$ \\
\hline Resultado & $\begin{array}{l}\text { Série não estacionária com } \\
\text { valor crítico de } 5 \% \text { e } 1 \% \text {. Não } \\
\text { rejeita-se a hipótese NULA de } \\
\text { raiz unitária. }\end{array}$ & $\begin{array}{l}\text { Série estacionária com } \\
\text { valor crítico de } 5 \% \text {. Rejeita- } \\
\text { se a hipótese NULA de raiz } \\
\text { unitária. }\end{array}$ & $\begin{array}{l}\text { Série não estacionária com } \\
\text { valor crítico de } 5 \% \text { e } 1 \% \text {. Não } \\
\text { rejeita-se a hipótese NULA de } \\
\text { raiz unitária. }\end{array}$ \\
\hline
\end{tabular}

Fonte: Resultados da pesquisa (2018).

Por fim, os resultados permitem concluir que a série de dados do preço produtor, atacado e varejo apresentam equilíbrio estável, já que foram constatadas com o teste de Raiz Unitárias Aumentado, séries estacionárias (sem raiz unitária).

\section{Elasticidade de Transmissão de Preços}

$\mathrm{Na}$ Tabela 1, são apresentadas as elasticidades de transmissão de preços do atacado e do varejo, influenciando os preços do produtor, as quais, foram obtidas pelo EViews, através da equação $\log P p=\log \alpha_{1}+\beta_{1} \log P a+\beta_{2} \log P v+\varepsilon_{1} \quad e$ comando $\log (\mathrm{pp}) \mathrm{c} \log (\mathrm{pa}) \log (\mathrm{pv})$.

TABELA 1 - Elasticidade de Transmissão de Preços (variável dependente LogPp). 


\begin{tabular}{|crrrr|}
\hline \hline Variable & Coefficient & Std. Error & t-Statistic & Prob. \\
\hline \hline C & -0.673719 & 0.150953 & -4.463116 & 0.0005 \\
LOC(P) & 0.807096 & 0.200709 & 4.021213 & 0.0011 \\
LOGV) & 0.085559 & 0.187134 & 0.457208 & 0.6541 \\
\hline \hline
\end{tabular}

Fonte: Resultados da pesquisa (2018).

De acordo com os resultados, os coeficientes das variáveis independentes $C$ e do preço do atacado (LOG(PA)) foram estatisticamente significativos a $1 \%$ (Rsquared $=0,778799$ ). Isto significa que uma variação de $1 \%$ no preço da batata no atacado $(\mathrm{Pa})$ provocaria uma variação no mesmo sentido de $0,807 \%$ no preço da batata para o produtor (Pp). Em outras palavras, o aumento de $1 \%$ no preço do atacado, causaria um aumento de $0,807 \%$ no preço do produtor. Já o coeficiente dos preços do varejo (LOG(PV)) não foram significativos para influenciar os preços do produtor.

Na Tabela 2, são apresentadas as elasticidades de transmissão de preços do produtor e do varejo, influenciando os preços do atacado, as quais, foram obtidas pelo EViews, através da equação $\log P a=\log \alpha_{1}+\beta_{1} \log P p+\beta_{2} \operatorname{logPv}+\varepsilon_{1}$ e comando $\log (\mathrm{pa}) \mathrm{c} \log (\mathrm{pp}) \log (\mathrm{pv})$.

TABELA 2 - Elasticidade de Transmissão de Preços (variável dependente LogPa)
\begin{tabular}{ccccc}
\hline \hline Variable & Coefficient & Std. Error & t-Statistic & Prob. \\
\hline C & 0.398938 & 0.177864 & 2.242941 & 0.0404 \\
LOG(PP) & 0.642762 & 0.159843 & 4.021213 & 0.0011 \\
LOG(PV) & 0.302377 & 0.148937 & 2.030238 & 0.0605 \\
\hline \hline
\end{tabular}

Fonte: Resultados da pesquisa (2018).

De acordo com os resultados, os coeficientes das variáveis independentes $C$ e do preço do atacado (LOG(PV)) foram estatisticamente significativos a $10 \%$ e a variável independente do preço do produtor (LOG(PP)) foi estatisticamente significativa a $1 \%$ (R-squared $=0,824063)$. Isto significa que uma variação de $1 \%$ no preço da batata no produtor (Pp) provocaria uma variação no mesmo sentido de $0,642 \%$ no preço da batata para o atacado $(\mathrm{Pa})$. Em outras palavras, se aumentar $1 \%$ o preço do produtor, o preço do atacado aumenta $0,642 \%$. Da mesma forma, uma variação de $1 \%$ nos preços do varejo (Pv) provocaria uma variação de $0,302 \%$ nos preços do atacado, ou seja, se eu aumentar $1 \%$ o preço do varejo, o preço do atacado aumentará $0,302 \%$.

Já, na Tabela 3, são apresentadas as elasticidades de transmissão de preços do produtor e do atacado, influenciando os preços do varejo, as quais, foram obtidas pelo EViews, através da equação $\operatorname{logPv}=\log \alpha_{1}+\beta_{1} \log P p+\beta_{2} \log P a+\varepsilon_{1} \quad$ e comando $\log (\mathrm{pv}) \mathrm{c} \log (\mathrm{pp}) \log (\mathrm{pa})$.

TABELA 3 - Elasticidade de Transmissão de Preços (variável dependente LogPv).

\begin{tabular}{ccccc|}
\hline \hline Variable & Coefficient & Std. Error & t-Statistic & Prob. \\
\hline \hline C & 0.624392 & 0.271305 & 2.301437 & 0.0361 \\
LOG(PP) & 0.160642 & 0.351354 & 0.457208 & 0.6541 \\
LOG(PA) & 0.712877 & 0.351130 & 2.030238 & 0.0605 \\
\hline \hline
\end{tabular}

Fonte: Resultados da pesquisa (2018).

De acordo com os resultados, os coeficientes das variáveis independentes $\mathrm{C}$ e do preço do atacado (LOG(PA)) foram estatisticamente significativos a 10\% (Rsquared $=0,639426$ ). Isto significa que uma variação de $1 \%$ no preço da batata no atacado $(\mathrm{Pa})$ provocaria uma variação no mesmo sentido de $0,712 \%$ no preço da batata para o varejo $(\mathrm{Pv})$. Em outras palavras, o aumento de $1 \%$ no preço do 
atacado, causaria um aumento de $0,712 \%$ no preço do varejo. Já o coeficiente dos preços do produtor (LOG(PP)) não foram significativos para influenciar os preços do varejo.

Assim, as elasticidades calculadas revelam que: (i) os preços do produtor são influenciados pelos preços do atacado; (ii) os preços do atacado são influenciados pelos preços do produtor e varejo; e, (iii) os preços do varejo são influenciados pelos preços do atacado.

Segundo Cunha et al. (2016) e Zanin e Meyer (2018) é fundamental compreender a formação e transmissão dos custos e preços em todos os níveis de comercialização para um determinando produto. Dessa forma, percebe-se a importância da análise dos diferentes componentes das margens de comercialização para melhor compreensão dos mercados agrícolas e políticas públicas.

\section{CONCLUSÕES}

Objetivou-se analisar as margens de comercialização da batata inglesa no período de novembro de 2015 a abril de 2017, especificamente em relação a flutuação dos preços e elasticidade de transmissão permitiu analisar

Os dados da pesquisa revelaram diferenças significativas e queda nos preços da batata inglesa para comercialização varejo, atacado e produtor na maior parte do período analisado. Além disso, o repasse desse valor nunca voltará integralmente para o produtor rural, sendo que o produtor tem uma participação de apenas 33,54\% em todo o período e grande parte do valor da venda do produto final fica com 0 varejo e atacado.

Quanto às margens de comercialização, 66,46\% em média do preço final pago pelo consumidor no mercado ficou no sistema para remunerar os serviços de comercialização, isto é, com o varejo e atacado. Ademais, através das margens relativas, percebe-se instabilidade do produtor, atacado e varejo no período, o que demonstra não consolidação entre os agentes de comercialização da batata.

Nota-se assim, necessidade de melhor organização dos produtores de batata para aumentaram sua competitividade frente ao atacado e varejo, e conseguirem melhores preços pagos pelo seu produto. Como também, percebe-se a importância da análise dos diferentes componentes das margens de comercialização para melhor compreensão dos mercados agrícolas e políticas públicas.

Quanto aos trabalhos futuros, sugere-se: (i) propor um modelo de análise de comercialização e previsão de preços para os Condomínios de Armazéns Rurais; (ii) realizar uma revisão sistemática de literatura nacional e internacional sobre modelos econométricos de comercialização e previsão de preços para grãos (soja ou milho); (iii) analisar séries temporais de comercialização de preços de grãos com o intuito de planejar o melhor momento para a logística, no que tange a atividade de transporte; (iv) utilizar outros modelos econométricos para analisar os dados desse trabalho; e, (v) realizar a mesma análise desse estudo para outros produtos agrícolas.

Quanto às limitações dessa pesquisa, a série de dados dos preços da batata poderia apresentar um maior período de tempo para análise.

\section{REFERÊNCIAS}

CARVALHAES, G.C.; CUNHA, C.A.; WANDER, A.E. Margem de comercialização do leite em Goiás. Revista de Política Agrícola, v. 24, n. 1, p. 47-61, 2015. 
CEPEA/ESALQ - Batata tem significativa queda de preços no fim de 2016. Disponível em: <http://www.hfbrasil.org.br/br/batata-cepea-batata-tem-significativaqueda-de-precos-no-fim-de-2016.aspx>. Acesso em junho de 2017.

CUNHA, C.A.; WANDER, A.E.; SILVA NETO, W.A. Integração entre mercados de bezerros dos estados de Mato Grosso do Sul e São Paulo, Brasil. Revista Espacios, v.37, n.13, 2016.

FGV - Fundação Getúlio Vargas. Índice Geral de Preços. 2017. Disponível em: $<$ http://portalibre.fgv.br/>. Acesso em maio de 2017.

FREITAS, D.G.F.; OLIVEIRA JUNIOR, J.N. "Mamão Hawai" - uma análise de preços e comercialização no Estado do Ceará. In: SOBER, 2004.

GUJARATI, D. Econometria Básica. Tradução da 4a Edição americana. Campus/Elsevier, 2006.

IBGE - Instituto Brasileiro de Geografia e Estatística. Levantamento sistemático da produção agrícola, abril de 2017. Disponível em: <http://www.ibge.gov.br/home/estatistica/indicadores/agropecuaria/lspa/defaulttab.sh tm>. Acesso em junho de 2017.

LOBO, O.A.; SILVA NETO, W.A. Transmissão de preços entre o produtor e varejo: evidências empíricas para o setor de carne bovina em Goiás. Conjuntura Econômica Goiana, n. 19, Dezembro/2011.

MENDES, J.T.G.; PADILHA JUNIOR, J.B. Agronegócio: uma abordagem econômica. São Paulo: Pearson Prentice Hall, 2007. p. 369.

PROHORT/CEASA - Canal Rural: Queda nos preços do tomate e da batata alivia inflação. $2016 . \quad$ Disponível em: http://www.canalrural.com.br/noticias/agricultura/queda-nos-precos-tomate-batataalivia-inflacao-61363. Acesso em junho de 2017.

REICHERT, L.J.; GOMES, M.C.; SCHWENGBER, J.E.; PEREIRA, A.S. Evaluation of organic potato production systems in the southern Rio Grande do Sul State, Brazil. Horticultura Brasileira, v. 31, n. 2, p. 220-230, 2013.

SANTOS, V.F.; PEREIRA, M.W.G.; BRAGA, M.J.; VIEIRA, W.C. Análise do preço do milho nos mercados externo e interno. Revista de Política Agrícola. Ano XVI - № 3 - Jul./Ago./Set. 2007.

SILVA, P.N.L.; FEXINA JUNIOR, R.; SANTOS, E.F. Conhecimento do consumidor e forma de apresentação da batata no mercado no Estado de São Paulo. Revista iPecege. 2(2): 46-55, 2016.

SILVA, J.J.C.; LAGES, A.M.G. Comercialização de produtos agropecuários em Alagoas: um estudo de margens de comercialização e transmissão de preços. Revista Nexos Econômicos. v. 5, n. 9, dez/2011. 
SILVA JÚNIOR, A.B.S.; LAGES, A.M.G.; SILVA, J.J.C. Margens e canais de comercialização da alface e tomate: especificidade do caso de Alagoas. Revista Economia Política Do Desenvolvimento, v. 4, n. 11, p. 7-20, 2011.

SOUZA, R.S.; VIANA, J.G.A. Tendência histórica de preços pagos ao produtor na agricultura de grãos do Rio Grande do Sul, Brasil. Ciência Rural, v.37, n.4, jul-ago, 2007.

ZANIN, V.; MEYER, L.G. Evolução da margem de comercialização da erva mate no Rio Grande do Sul. Revista IPecege, v. 4, n. 1, p. 7-18, 2018. 